reveals an overall mortality rate of $5.7 \%$. Two hundred and fifty patients are in normal health leading active lives. Conversion to total ileostomy has been necessary in 14 cases $(5 \%$ of operative survivors), because of the development of carcinoma of the rectum, stricture, incontinence, or other complications.

The indications for this type of operation in acute and chronic diseases are discussed. It is suggested that the best results in the surgical management of patients with ulcerative colitis can be achieved only in special centres.
Acknowledgement is due to Lille Chirurgical for permission to publish Figs. 2 and 3.

REFERENCES

Aylett, S. O. (1953). Brit. med. F., 2, 1348.

(1960). Ann. roy. Coll. Surg. Engl., 27, 260.

(1963). Proc. roy. Soc. Med., 56, 183.

(1964). Lille chir., 19, 249.

Cattan, R. (1960). Proc. Int. Congr. Gastroent., 499.

Goligher, J. C. (1962). Trans. med. Soc. Lond., 78, 17.

Turnbull, R. (1965). Personal communication.

\title{
Mortality Reduction in a Coronary Care Unit
}

\author{
ALAN J. GOBLE,* M.D., M.R.C.P., F.R.A.C.P.; GRAEME SLOMAN,** M.B., B.SC., M.R.C.P., M.R.C.P.ED., M.R.A.C.P. \\ JAMES S. ROBINSON, ${ }^{*} \dagger$ M.B., M.R.A.C.P.
}

Brit. med. F., 1966, 1, 1005-1009

The concept of special care units for patients with acute myocardial infarction arises from the recognition that $60 \%$ of the deaths in these patients occur in the first week (Honey and Truelove, 1957 ; Wahlberg, 1963). Sudden deaths from cardiac arrest are common during this period. The development of external cardiac massage (Kouwenhoven et al., 1960), external electrical defibrillation (Zoll et al., 1956 ; Lown et al., 1962), and external electrical pacing (Zoll, 1952) have led to continuous electrocardiographic monitoring with a view to the immediate detection and correction of ventricular fibrillation and asystole (Brown et al., 1963 ; Day, 1963 ; Robinson et al., 1964 ; Julian et al., 1964a). Monitoring has led to the recognition that abnormalities of conduction and excitation occur in 90 to $95 \%$ of patients with myocardial infarction (Julian et al., 1964b).

A specially staffed and equipped coronary care unit should result in a reduction of mortality through immediate effective resuscitation of some patients following cardiac arrest, through the rapid correction of those arrhythmias which may be lifethreatening, possibly through earlier control of hypotension, cardiac failure, and cardiogenic shock, and perhaps through the prevention of some of these complications. The coronary care unit in the Royal Melbourne Hospital was established in an attempt to define the potential of such units in achieving these aims. This paper presents the results in the first 150 patients.

\section{Materials}

Patients with acute myocardial infarction were admitted to the two-bed unit as beds became available, but preference was given to men. There were 144 men and 6 women. Ages ranged from 36 to 87 , with a mean of 57 years. The diagnosis of acute myocardial infarction was based upon a history of ischaemic cardiac pain lasting more than 30 minutes, occurring within the previous 24 hours, and with electrocardiographic confirmation, this consisting of abnormal $Q$ waves, ST segment elevation, and established or developing $\mathrm{T}$-wave inversion.

Patients remained in the unit for a period of three days after the last pain or following cardiac arrest. They were divided into three groups-" mild," "severe," and "cardiogenic shock "-classification being made after pain had been relieved and oxygen administered for at least 30 minutes.

\footnotetext{
* From the Cardiac Department, the Royal Melbourne Hospital, Melbourne, Victoria, Australia. t Research Assistant, National Heart Foundation of Australia, in receipt
of Grant-in-Aid G162.
}

Mild cases were those in which there was no hypotension or evidence of cardiac failure, apart from a transient rise in jugular venous pressure. There were 67 mild cases.

Severe cases were those in which there was evidence of circulatory embarrassment, indicated by hypotension (systolic arterial pressure below $100 \mathrm{~mm}$. $\mathrm{Hg}$ ) or cardiac failure with persisting moist sounds at the lung bases (Freis et al., 1952). There were 70 severe cases.

Cardiogenic shock was considered present when the systolic arterial pressure remained below $80 \mathrm{~mm}$. $\mathrm{Hg}$, associated with pallor, cyanosis, sweating, cold skin, and oliguria (Binder et al., 1955). There were 13 cases in this group.

\section{Methods}

The staffing and details of equipment and methods used have been reported elsewhere (Robinson et al., 1964, 1965). A trained nursing sister was on duty at all times and a roster of medical staff was on call.

On hand were a self-expanding bag respirator and R-M resuscitator connected to a face-mask, to deliver oxygen from a piped wall supply, and a defibrillator and external-internal pacemaker. Automatic-demand external pacing was not used. All drugs likely to be required for cardiac emergencies were kept in the unit. Facilities for tracheal intubation and tracheostomy were readily available.

Bed heads were removed for easy access to the patient; a large single-bed board was fixed under the mattress to facilitate external cardiac massage. Each patient was connected by chest electrodes to an electrocardiograph recorder, cathode-ray oscilloscope, heart-rate meter, and rate-activated alarm. An automatic recorder was activated when a predetermined variation in the heart rate persisted for more than eight seconds. Additional records were made at hourly intervals or if changes were observed in the oscilloscope tracings. Arterial pressure was obtained by cuff at hourly intervals.

The patients were allowed to adopt a position of comfort in bed and received a light diet with no added salt. In the absence of shock a bedside commode was used, and if there was difficulty with micturition patients sat on the side of the bed. Unless there was a specific contraindication, all patients received phenindione as an anticoagulant. Analgesia was obtained with papaveratum. Sodium amylobarbitone or promethazine hydrochloride was given to produce sedation. Wakeful or apprehensive patients received sodium pheno- 
barbitone $200 \mathrm{mg}$. intramuscularly as required. Oxygen was administered throughout the period in the unit by plastic facial mask or by intranasal catheter. Patients were advised regarding the pattern of management and reassured, with the aim of producing a sense of security. On leaving the unit, usually after three or four days, they were transferred to the general wards of the hospital and were reviewed as out-patients six weeks after the onset of infarction.

Cardiac failure was treated with mercurial and thiazide diuretics and digitalization. Hypotension was treated with metaraminol intramuscularly to maintain the arterial pressure over $90 \mathrm{~mm}$. Hg. Cardiogenic shock was treated with intravenous metaraminol or noradrenaline, aiming to keep the arterial systolic pressure above $90 \mathrm{~mm}$. $\mathrm{Hg}$, together with intravenous and intramuscular hydrocortisone.

Patients with frequent ventricular ectopics received intramuscular procainamide $250-500 \mathrm{mg}$. six-hourly, or in some cases propranolol intravenously or orally (Sloman et al., 1965), followed by oral quinidine sulphate. Supraventricular tachycardia and atrial fibrillation were treated by digitalization. If life-threatening, timed direct-current countershock reversion was used (Lown et al., 1962). Ventricular tachycardia was treated with procainamide $500-1,000 \mathrm{mg}$. intravenously, and, if continued, by direct-current countershock. Patients who were hypotensive with an arrhythmia received intramuscular or intravenous metaraminol prior to these treatments.

Atrioventricular block was treated with intramuscular or oral isoprenaline hydrochloride and intravenous hydrocortisone, followed by oral steroids (Dall and Buchanan, 1962). Internal pacing with catheter electrode was undertaken in two cases (Blackmon et al., 1964).

Cardiac arrest was treated by external cardiac massage (Kouwenhoven et al., 1960) combined with emergency ventilation by means of the $\mathrm{R}-\mathrm{M}$ resuscitator and a pharyngeal airway. In the earlier cases alternating-current countershock was used for ventricular fibrillation (Zoll et al., 1956) and in the later cases direct-current countershock (Lown et al., 1962). When arrest was due to asystole external pacing was used (Zoll, 1952). In two patients internal pacing by catheter-electrode was employed (Blackmon et al., 1964). A cut-down on a leg vein at the ankle was undertaken immediately for the administration of $150-200 \mathrm{mEq}$ of sodium bicarbonate $8.4 \%$ solution (Ledingham and Norman, 1962). In refractory cases countershock was repeated. In patients with ventricular fibrillation intravenous procainamide $500-1,000 \mathrm{mg}$. was given and further attempts at reversion were undertaken. Patients with recurrent ventricular fibrillation received intravenous procainamide or propranolol 5-10 mg. intravenously (Sloman et al., 1965). Patients with asystole were given isoprenaline hydrochloride 0.1-0.2 mg. intravenously and hydrocortisone $300 \mathrm{mg}$. intravenously.

Patients with respiratory difficulty, following cardiac massage, due to rib fractures or other causes underwent tracheostomy and were ventilated with a Bird intermittent positive-pressure respirator.

Resuscitation attempts in all cases were continued or repeated until it was found impossible to maintain a circulation. After successful resuscitation patients who had an episode of ventricular fibrillation received intramuscular procainamide and subsequently oral quinidine or oral propranolol up to $10 \mathrm{mg}$. t.d.s. Those who had had asystole received intramuscular hydrocortisone and isoprenaline hydrochloride.

\section{Results}

\section{Cardiac Arrest and Mortality}

The results of resuscitation attempts in patients who developed cardiac arrest are set out in Table I.
TABLE I.-Incidence of Ventricular Fibrillation (V.F.) and Asystole in 150 Patients with Acute Myocardial Infarction Correlated with the Patients' Survival

\begin{tabular}{|c|c|c|c|c|c|c|}
\hline Class & $\begin{array}{l}\text { No. of } \\
\text { Cases }\end{array}$ & $\begin{array}{l}\text { First } \\
\text { Arrest }\end{array}$ & No. & $\begin{array}{c}\text { Successful } \\
\text { Resuscitation }\end{array}$ & $\begin{array}{l}\text { Hospital } \\
\text { Survival }\end{array}$ & $\begin{array}{c}\text { Long-term } \\
\text { Survival }\end{array}$ \\
\hline Mild . & 67\{ & $\begin{array}{l}\text { V.F. } \\
\text { Asystole }\end{array}$ & 5 & $\frac{5}{-}$ & 5 & 5 \\
\hline Severe & 70\{ & $\begin{array}{l}\text { V.F. } \\
\text { Asystole }\end{array}$ & $11 \frac{1}{5}$ & $\begin{array}{l}3 \\
3\end{array}$ & $\underline{2}$ & -2 \\
\hline Shock & 13\{ & $\begin{array}{l}\text { V.F. } \\
\text { Asystole }\end{array}$ & $\overline{7}$ & 二 & 二 & - \\
\hline Total & 150\{ & $\begin{array}{l}\text { V.F. } \\
\text { Asystole }\end{array}$ & $\begin{array}{l}16 \\
12\end{array}$ & $\begin{array}{l}8 \\
3\end{array}$ & -7 & 7 \\
\hline
\end{tabular}

Of the 150 cases 67 were classified as mild. Of these, five developed ventricular fibrillation on the first day in the unit; all were successfully resuscitated and were alive at six weeks. No patients in this group developed asystole.

Of the 70 severe cases 11 developed ventricular fibrillation, three being successfully resuscitated and two of these being alive at six weeks. Five patients in this group developed asystole ; three were successfully resuscitated, but died later in hospital.

Of the 13 patients with cardiogenic shock seven developed asystole, none being successfully resuscitated. There were no cases with ventricular fibrillation as the initial mode of cardiac arrest in this group. Four patients in this group died with "power failure" of the left ventricle (Hellerstein, 1963): in these cases, though the electrocardiogram showed a continuing sinus, nodal, or idioventricular rhythm, the ventricular contractions were inadequate to generate a pulse. This method of death was common in subjects who, after attempted resuscitation, died from asystole or ventricular fibrillation in the severe group, and in the patients who died after asystole in the cardiogenic shock group.

\section{Severity and Mortality}

Of the 67 mild cases two died in hospital—one from a stroke on the twelfth day and one suddenly in the ward on the fifteenth day. Thus 65 patients left hospital alive; one died at home on the 35 th day, leaving 64 who survived at least six weeks, including the five who developed ventricular fibrillation on the first day in the coronary care unit (Fig. 1).

\begin{tabular}{|c|c|c|c|}
\hline Deatis & + & + & \multirow{3}{*}{$\frac{67 \text { Cases }}{2 \text { deaths }} \begin{array}{c}65 \text { survivors } \\
(5 \text { resuscitated })\end{array}$} \\
\hline Doy & 1233450788101112 & $14151017: 8192021$ & \\
\hline $\begin{array}{l}\text { Successful } \\
\text { Resuscitation }\end{array}$ & 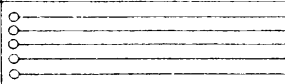 & $\stackrel{\longrightarrow}{\longrightarrow}$ & \\
\hline
\end{tabular}

FIG. 1.- Incidence and timing of deaths in 67 patients with mild myocardial infarction. Open circles indicate successful resuscitation from ventricular fibrillation. The arrows indicate the duration of survival after successfal resuscitation.

Among the severe group of 70 cases there were 32 deaths in hospital ; 38 patients survived and were alive at six weeks, including two resuscitated from ventricular fibrillation on the first day. Four patients resuscitated from cardiac arrest (one from ventricular fibrillation and three from asystole) died later - two while in the unit and two in the hospital wards. In this group there were nine deaths on the first day in the unit; later deaths continued both in the unit and in the wards of the hospital from cardio-respiratory failure, cardio-renal failure, cardiac arrest, and other causes (Fig. 2).

Fig. 3 sets out the mortality results in the severe cases when divided into three groups. Those with hypotension alone (with a systolic arterial pressure below $100 \mathrm{~mm}$. $\mathrm{Hg}$ after relief of pain and administration of oxygen for 30 minutes) constituted only 5 of the 70 cases. There was only one death in this group: this patient died suddenly in the ward on the seventeenth day, having been successfully resuscitated from 
asystole on the first day in the coronary care unit. Among 48 cases with cardiac failure whose arterial systolic pressure was greater than $100 \mathrm{~mm}$. $\mathrm{Hg}$ there were four deaths on the first day and 13 subsequent deaths, occurring evenly through the next three weeks. The two patients with severe infarction who were successfully resuscitated from ventricular fibrillation were among the 31 who survived in hospital and all of whom were alive at six weeks. Of the 17 patients with both hypotension and cardiac failure 14 died in hospital, all within the first two weeks, two having been successfully resuscitated from cardiac arrest in the unit. The three patients who were discharged from hospital were alive at six weeks.

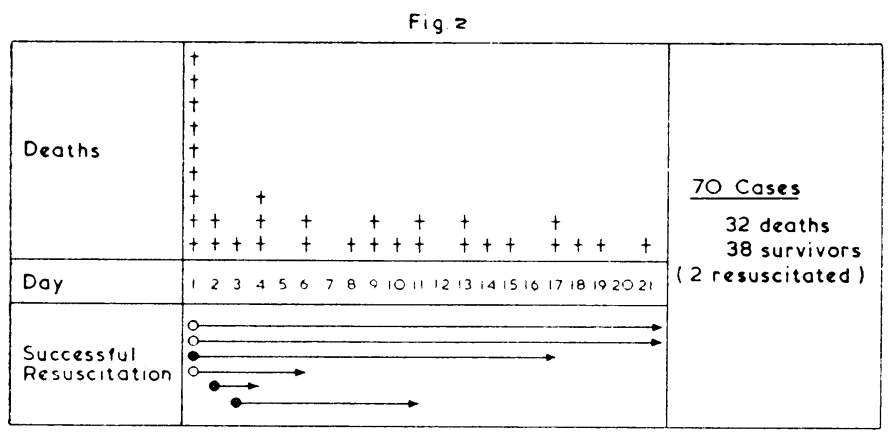

\begin{tabular}{|c|c|c|}
\hline HYPOTENSIO & Fig. 3 & \\
\hline Deaths & + & \multirow{3}{*}{ 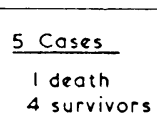 } \\
\hline Day & $1234507801011121314151017: 8102021$ & \\
\hline $\begin{array}{l}\text { Successiul } \\
\text { Resuscitation }\end{array}$ & $\bullet$ & \\
\hline
\end{tabular}
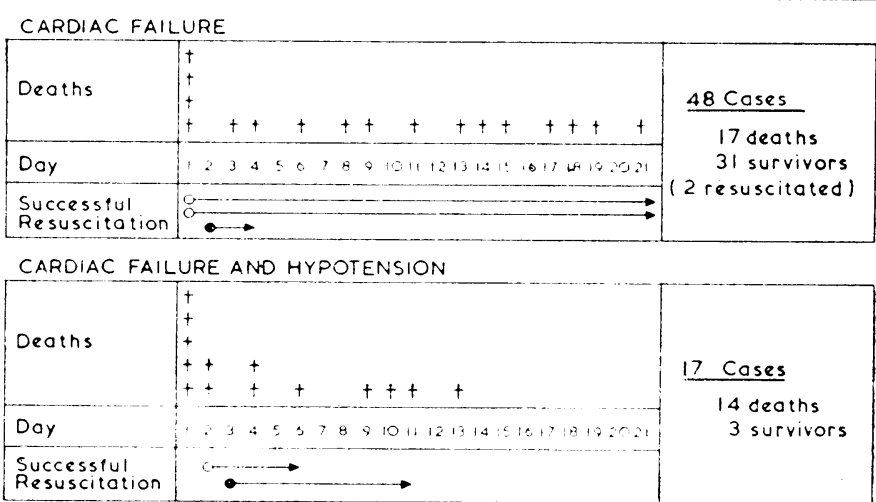

FIg. 2.-Incidence and timing of deaths in 70 patients with severe myocardial infarction. Open circles indicate successful resuscitation from ventricular fibrillation; closed circles indicate successful resuscitation from asystole. Arrows indicate duration of survival after successful resuscitation. Fig. 3.-Incidence and timing of survival after successful resuscitation. FIG. 3.- Incidence and timing of death in 70 patients with sion, cardiac failure, or hypotension and cardiac failure combined. Open circles indicate successful resuscitation from ventricular fibrillation ; circles indicate successful resuscitation from ventricular fibrillation;
closed ciriles indicate successful resuscitation from asystole. Arrows indicate duration of survival after successful resuscitation.
There was only one survivor from the 13 patients with cardiogenic shock, this patient being clinically indistinguishable from the other 12 cases, except that he had no serious complicating arrhythmia. Nine patients died on the first day ; three died later-two in the unit and one in the medical ward (Fig. 4).

\begin{tabular}{|c|c|c|}
\hline Deaths & $\begin{array}{l}t \\
t \\
+ \\
+ \\
+ \\
+ \\
+ \\
+ \\
+ \\
+++ \\
+\end{array}$ & 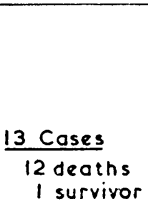 \\
\hline Day & 123456789101112131415101718192021 & \\
\hline $\begin{array}{l}\text { Successful } \\
\text { Pesuscitation }\end{array}$ & & \\
\hline
\end{tabular}

FIG. 4.- Incidence and timing of deaths in 13 patients with cardiogenic shock complicating myocardial infarction. No patients were successfully resuscitated in this group.

\section{Arrhythmia and Mortality}

The hourly strips of electrocardiographic records, together with recordings made when a change was noted in the oscilloscope, revealed intermittent variations of excitation or conduction in approximately $90 \%$ of cases. These included atrial ectopics, atrial parasystole, wandering atrial pacemaker, sinus tachycardia, sinus bradycardia, sinus arrhythmia, nodal ectopics, nodal rhythm, ventricular ectopics, long P-R interval, Wenckebach phenomena, left bundle-branch block, right bundle-branch block, and intraventricular conduction block.

The more serious arrhythmias are set out in Table II, together with the mortality associated with each arrhythmia in the unit and subsequently in the hospital wards. Ventricular fibrillation and asystole are not included in this table. Sixty patients developed one or more of the arrhythmias listed in the table. These patients accounted for 37 of the total of 46 deaths. Ventricular tachycardia, occurring in 22 patients, was the most common arrhythmia, idioventricular rhythm the most prognostically grave, and atrial fibrillation the most innocent. Supraventricular tachycardias included cases with atrial tachycardia and atrial flutter, each with or without bundlebranch block. Differentiation from ventricular tachycardia was difficult in those with bundle-branch block, and the distinction may well be inaccurate in some cases.

In the 67 mild cases there were 15 patients with serious arrhythmias, with only one later death. There were 33 patients who developed one or more serious arrhythmias in 70 cases with severe infarction. Of the 32 patients in this group who died 24 had serious arrhythmias in the unit; nine of these patients died in the wards after leaving the unit. Twelve of the 13 patients with cardiogenic shock had serious arrhythmias, 11 dying in the unit and one subsequently.

TAble II.-Incidence of Serious Arrhythmias Complicating Acute Myocardial Infarction in 150 Patients, Together with Incidence of Deaths in the Coronary Care Unit and Subsequent Deaths in the Medical Wards. Many Patients had Multiple Arrythmias

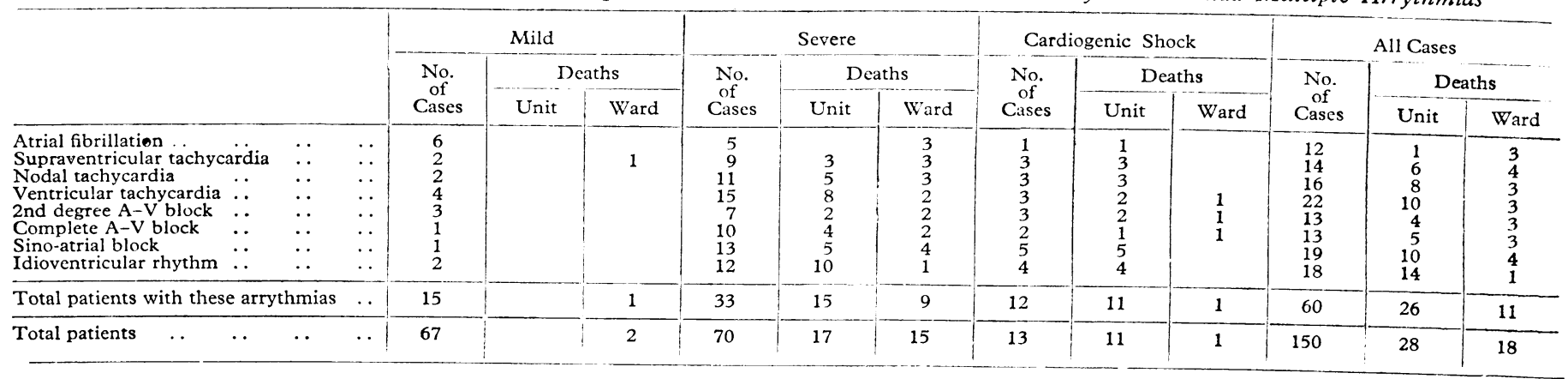

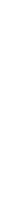




\section{Discussion}

Continuous electrocardiographic monitoring of patients with acute myocardial infarction permits the immediate detection of cardiac arrest and its correction in many cases (Brown et al., 1963 ; Day, 1963, 1965 ; Robinson et al., 1964). Success depends upon the immediate institution of efficient resuscitation, the skill of the resuscitation team, and the availability of equipment and materials. The establishment of a "coronary care unit" within a hospital assures that each patient has the maximum chance of successful resuscitation (Imboden, 1964).

Of great importance in determining the outcome is the severity of the myocardial infarction as judged by the haemodynamic effects of the infarct (Freis et al., 1952; Binder et al., 1955) and the incidence of arrhythmias and other complications (Honey and Truelove, 1957). While there is a natural tendency to admit to a coronary care area those patients who are most severely ill following myocardial infarction, this may not be the correct procedure if such a step prevents the less ill patient from being continuously monitored (Robinson et al., 1965). All five patients who developed cardiac arrest in the mild group of 67 patients were successfully resuscitated, and were still alive from two years to seven months after the episode of ventricular fibrillation. The two long-term survivors following ventricular fibrillation in the severe group of 70 patients had cardiac failure, but were not also hypotensive. No patient with cardiogenic shock or with both cardiac failure and hypotension survived more than eight days after cardiac arrest, whether from ventricular fibrillation or asystole. Thus only seven patients out of a total of 28 lived to leave hospital after an episode of cardiac arrest in the coronary care unit (Table I). This suggests that monitoring with a view to the detection and correction of cardiac arrest should be preferred for the patients with the least circulatory embarrassment following their infarction.

Our experience confirms the view of Day $(1963,1965)$ that cardiac arrest in these patients is most likely to occur on the first day after infarction, with a lesser incidence during the next four days (Figs. 2, 3, and 4).

Hospital mortality was reduced to two out of 67 cases in the mild group, the five patients who developed ventricular fibrillation all surviving. Further prevention of mortality may also have been achieved among 15 mild cases by control of potentially serious arrhythmias, the early recognition and correction of which was made possible by continuous monitoring (Table II).

There were five patients who were hypotensive without evidence of cardiac failure. In one of these death occurred on the seventeenth day, after successful resuscitation from asystole on the first day (Fig. 3). The overt mortality reduction in patients with cardiac failure without hypotension is limited to two patients, who were still alive six months and four months after ventricular fibrillation. It is notable, however, that 10 of the 17 patients who died in this group died in the general wards of the hospital after leaving the unit. This suggests that death in some of these cases may have occurred earlier if they had not received intensive care in the unit during the first few days of their illness.

It is noted that in those patients with cardiac failure and hypotension (Fig. 3) there were nine deaths in the first four days, two delayed deaths following successful resuscitation, three deaths in the general hospital wards, and only three survivors. It is doubted whether the admission of these patients to the coronary care unit significantly affected the outcome. Many of them would have satisfied the criteria of other workers for cardiogenic shock, as their systolic arterial pressures varied between 100 and $80 \mathrm{~mm}$. $\mathrm{Hg}$ and they were cold, sweaty, and cyanosed (MacKenzie et al., 1964). The 13 patients in our series with cardiogenic shock had systolic arterial pressures below $80 \mathrm{~mm}$. $\mathrm{Hg}$ despite 30 minutes of oxygen administration, thereby satisfying the criteria of Binder et al. (1955). Although the one survivor from these 13 patients required special nursing care, monitoring contributed nothing to the outcone, he having no arrhythmia or arrest. It is suggested that attempts at resuscitation of patients with systolic pressures below $100 \mathrm{~mm}$. $\mathrm{Hg}$, prostration, and cardiac failure will usually fail.

Table II demonstrates the association between potentially serious arrhythmias detected in the unit and deaths both in the unit and in the general medical wards after leaving it. This indicates the need for prolonged careful observation of patients whose course in the unit is complicated by these arrhythmias. The incidence of the arrhythmias in the severe group of cases and the association between them and both early and delayed deaths indicate that these patients, particularly, should be kept under continued monitoring and observation. Fig. 2 shows the occurrence of deaths over a three-week period in these severe cases, indicating that they require special care for this period. In the mild cases this appears to be not necessary (Table II), and in those patients with cardiogenic shock early mortality makes this consideration irrelevant (Table II, Fig. 4).

The effectiveness of resuscitation in patients with ventricular fibrillation is shown in Table I. It is also apparent that ventricular fibrillation is more likely to occur in the less severely ill patients, while asystole occurs with increasing frequency as the severity of the infarction increases. Further, in the three patients successfully resuscitated from asystole death occurred later in hospital. Minogue et al. (1964) report one long-term survivor who was resuscitated from cardiac arrest due to asystole complicating myocardial infarction and cardiac failure. Day (1965) reports five cases resuscitated from asystole. It is notable that his patients were connected to a demand external pacemaker, supplying external direct-current pacing shocks, if the $\mathrm{R}$ wave of the electrocardiogram was not detected for eight seconds. Two of his reported cases had complete atrioventricular block, and it is therefore possible that the episodes in these cases were Stoke-Adams attacks with ventricular standstill but with continued atrial activity. Also we have often observed reduction in the voltage of the $R$ wave significant enough to trigger the automatic alarm (with which direct-current demand pacing would be coupled) when the patient moves from one position to another in the bed. Thus it is possible that some of his patients were not in asystole. We do not consider that demand external pacing has a place in the treatment of cardiac arrest. It is our experience that asystole complicating myocardial infarction is of much more grave prognostic significance than is ventricular fibrillation.

Recurrent ventricular fibrillation is likely to occur particularly in previously resuscitated patients if the infarct is severe (Robinson et al., 1965). It is therefore our practice to administer procainamide, quinidine, or propranolol to all patients after resuscitation from ventricular fibrillation and to continue one or more of these drugs for several days. Recent experience with propranolol (Sloman et al., 1965) suggests that this is the preferred treatment. Recurrence of asystole in patients with complete atrioventricular block, or following resuscitation from an initial episode of asystole, is also frequent. The experience of Blackmon ct al. (1964) with internal catheter electrode pacing appears to offer a possible method of controlling this. Catheter electrode pacing was used in two of our later cases with complete atrioventricular block and asystole, with only temporary benefit. Pacing by needle electrodes through the chest wall is a possible method of maintaining a heart beat pending insertion of the catheter electrode. The high mortality from asystole (Table I) would justify these measures in patients with mild or severe infarction, but it is felt that the outcome in patients with cardiogenic shock would not be affected, as death in these cases is commonly from terminal " power failure" (Hellerstein, 1963).

Continuous electrocardiographic monitoring after acute myocardial infarction has demonstrated alterations in excitation 
and conduction in 90 to $95 \%$ of patients (Brown et al., 1963 ; Julian et al., 1964a ; Robinson, 1965). Most of the minor abnormalities are of little immediate or prognostic significance. However, frequent or multifocal ventricular ectopics may precede ventricular tachycardia or ventricular fibrillation (Smirk and Palmer, 1960 ; Julian et al., 1964b). Because of this, it is our practice to administer parenteral procainamide or propranolol if frequent ventricular ectopic beats appear.

Though monitoring leads to recognition of a high incidence of potentially serious arrhythmias (Table II), these are often self-terminating within minutes or hours and may not lead to circulatory cmbarrassment. In these circumstances cautious drug treatment of the particular arrhythmia is indicated. It is only for those arrhythmias which produce a fall in arterial pressure, or other evidence of circulatory embarrassment, that timed electrical countershock (Lown et al., 1962) or catheter electrode pacing (Blackman ot al., 1964) is indicated.

The establishment of a coronary care unit has led to a greater awareness of the problems of cardiac arrest and resuscitation throughout this hospital. Observation of patients in the general medical wards has improved and an increasing number of medical and nursing staff have become proficient in handling cardiac emergencies, which may arise at any time. It is nevertheless considered that all patients with myocardial infarction should be admitted to a coronary care unit in the hospital for the first four or five days. Patients who develop cardiac failure and potentially serious arrhythmias in this period are likely to die, following a further arrhythmia, after transfer from this unit to the general wards of the hospital. These more seriously ill patients should therefore be kept in the coronary care unit for up to three weeks. This type of management necessitates the careful psychological handling of patients. Seriously ill patients would be best kept in an area adjacent to, but separate from, the less ill in order that patients be as little disturbed as possible by the attentions paid to others. Anxiety-provoking situations are important while patients are in hospital, as they may lead to later psychological disability and failure of complete social rehabilitation (Goble et al., 1963). Acute anxiety appears to be a factor in the production of ventricular fibrillation in some cases (Goble, 1965). Though anxiety appears not to have been induced in patients admitted to the small two-bed ward used for the purpose of this study, a large unit with a greater turnover could prove psychologically damaging to some patients. Thus the allaying of fears by careful repeated discussion along with the judicious use of sedation is considered important for all patients. The management of patients under potentially stressful circumstances is more than merely a physical problem.

\section{Summary}

The methods and results of observation and treatment of the first 150 patients with acute myocardial infarction admitted to a special coronary care unit are presented.

Seven patients resuscitated from cardiac arrest survived their period in hospital and were still alive four months to two years after the first episode of arrest. Four other patients were successfully resuscitated but died later in hospital; three of these patients had complete asystole. The seven survivors and one who died later in hopital had ventricular fibrillation.

Ventricular fibrillation tended to be the cause of cardiac arrest in milder cases. Asystole occurred in the more severely ill patients with cardiac failure and "cardiogenic shock."

It is suggested that mortality reduction is also achieved, or death delayed, in a coronary care unit through earlier detection and control of cardiac failure, hypotension, and arrhythmias.

Potentially serious arrhythmias were detected in 60 of the 150 patients. It is suggested that in selected patients with cardiac failure and serious arrhythmias continued special care is required for two to three weeks from the onset of infarction to reduce later deaths.

A coronary care unit is an important factor in reducing mortality from myocardial infarction. Such units should be established in all large hospitals dealing with acute cases.

We are indebted to the physicians and other medical staff of the Royal Melbourne Hospital for their co-operation in this study and to the National Heart Foundation of Australia and the Committee of Management of the Royal Melbourne Hospital for their support. We thank particularly Dr. K. J. Grice and Professor R. R. H. Lovell for their co-operation and advice, and the nursing and resident staff who contributed so much to the care of the patients.

\section{REFERENCES}

Binder, M. J., Ryan, J. A., Marcus, S., Mugler, F., Strange, D., and Agress, C. M. (1955). Amer. F. Med., 18, 622.

Blackmon, J. R., Bruce, R. A., Cobb, L. A., and Dodge, H. T. (1964). Circulation, 30, Suppl. No. 3, p. 49.

Brown, K. W. G., MacMillan, R. L., Forbath, N., Mel'Grano, F., and Scott, J. W. (1963). Lancet, 2, 349.

Dall, J. L. C., and Buchanan, J. (1962). Ibid., 2, 8.

Day, H. W. (1963). Dis. Chest, 44, 423.

- (1965). Amer. F. Cardiol., 15, 51.

Freis, E. D., Schnaper, H. W., Johnson, R. L., and Schreiner, G. E. (1952). 7. clin. Invest., 31, 131.

Goble, A. J. (1965). Brit. Heart 7., 27, 62.

- Adey, G. M., and Bullen, J. F. (1963). Med. 7. Aust., 2, 975.

Hellerstein. H. K. (1963). In Electrocardiographic Interpretation, edited by J. W. Hurst and N. K. Wenger, p. 257. Mcgraw-Hill, New York.

Honey, G. E., and Truelove, S. C. (1957). Lancet, 1, 1155, 1209.

Imboden, C. A., jun. (1964). Med. Ann. D.C., 33, 442.

Julian, D. G., Valentine, P. A., and Miller, G. G. (1964a). Med. F. Aust., 1,433 .

Kouwen (1964b). Amer. 7. Med., 37, 915.

ouwenhoven, W. B., Jude, J. R., and Knickerbocker, G. G. (1960). F. Amer. med. Ass., 173, 1064.

Ledingham, I. McA., and Norman, J. N. (1962). Lancet, $2,967$.

Lown, B., Amarasingham, R., and Neuman, J. (1962). f. Amer. med. Ass., $182,548$.

Mackenzic, G. J., Taylor, S. H., Flenley, D. C., McDonald, A. H., Staunton, H. P., and Donald, K. W. (1964). Lancet, 2, 825 .

Minogue, W. F., Smessart, A. A., and Grace, W. J. (1964). Amer. F. Cardiol., 13, 25.

Robinson, J. S. (1965). Amer. Heart 7., 69, 285.

Sloman, G., Mathew, T. H., and Goble, A. J. (1965). Ibid., 69, 740 .

Shi and McRae, C. (1964). Med. F. Aust., 1, 427.

Shillingford, J. P., and Thomas, M. (1964). Lancet, 2, 1113.

Sloman, G., Robinson, J. S., and McLean, K. (1965). Brit. med. f., 1, 895 .

Smirk, F. H., and Palmer, D. G. (1960). Amer. F. Cardiol., 6, 620.

Wahlberg, F. (1963). Amer. Heart f., 65, 749.

Zoll, P. M. (1952). New Engl. 7. Med., 247, 768. (1956). Ibid., 254, 727. 